\title{
Clinical Evaluation of the Failure Rate of Metallic Brackets Bonded with Orthodontic Composites
}

\author{
Fábio Lourenço ROMANO ${ }^{1}$ \\ Rodrigo Alexandre VALÉRIO ${ }^{1}$ \\ Jaciara Miranda Gomes-SILVA ${ }^{1}$ \\ José Tarcísio Lima FERREIRA ${ }^{1}$ \\ Gisele FARIA $^{2}$ \\ Maria Cristina BORSATTO ${ }^{1}$
}

\author{
${ }^{1}$ Department of Pediatric Clinics, Preventive and Community Dentistry, Ribeirão Preto Dental School, \\ USP - University of São Paulo, Ribeirão Preto, SP, Brazil \\ ${ }^{2}$ Department of Restorative Dentistry, Araraquara Dental School, \\ UNESP - Univ Estadual Paulista, Araraquara, SP, Brazil
}

\begin{abstract}
The purpose of the present study was to evaluate in vivo the failure rate of metallic brackets bonded with two orthodontic composites. Nineteen patients with ages ranging from 10.5 to 38.7 years needing corrective orthodontic treatment were selected for study. The enamel surfaces from second premolars to second premolars were treated with Transbond Plus-Self Etching Primer (3M Unitek). Next, 380 orthodontic brackets were bonded on maxillary and mandibular teeth, as follows: 190 with Transbond XT composite (3M Unitek) (control) and 190 with Transbond Plus Color Change (3M Unitek) (experimental) in contralateral quadrants. The bonded brackets were light cured for $40 \mathrm{~s}$, and initial alignment archwires were inserted. Bond failure rates were recorded over a six-month period. At the end of the evaluation, six bond failures occurred, three for each composite. Kaplan-Meyer method and log-rank test (Mantel-Cox) was used for statistical analysis, and no statistically significant difference was found between the materials $(\mathrm{p}=0.999)$. Both Transbond XT and Transbond Plus Color Change composites had low debonding rates over the study period.
\end{abstract}

Key Words: orthodontic brackets, orthodontics, debonding.

\section{INTRODUCTION}

During the orthodontic corrective mechanics, bracket bonding is of great importance for achieving a satisfactory outcome, since the desired dental movement depends on it. In addition, bracket debonding during treatment implies an increase in treatment time, harm to enamel and increase in chair time resulting from the re-bonding procedure $(1,2)$.

The procedures for boding orthodontic accessories to tooth enamel have significantly evolved since its introduction in the 1960s (3). New materials have been developed for performing this procedure. Indeed, the conventional bonding technique has currently been modified with the use of self-etching agents prior to the bracket attachment with composites. These new products are aimed at simplifying the initial procedures, reducing chair time and consequently benefiting both patient and orthodontist. This modification was tested in several laboratory experiments and clinical trials (4-7), with satisfactory results in both types os studies.

A new light-cured composite (Transbond Plus Color Change; 3M Unitek, Monrovia, CA, USA) has been recently developed. Apart from its hydrophilic characteristics, this orthodontic composite has changes in color after photoactivation in order to make excess removal easier. Additionally, it can be used to bond both metallic and ceramic brackets.

The purpose of the present study was to evaluate in vivo the failure rate of metallic brackets bonded with either Transbond XT (TXT) (3M Unitek) or Transbond Plus Color Change (TPCC) composites. Secondarily,

Correspondence: Prof. Dr. Fábio Lourenço Romano, Faculdade de Odontologia de Ribeirão Preto, USP, Departamento de Clínica Infantil, Odontologia Preventiva e Social, Avenida do Café, S/N, Monte Alegre, 14040-904 Ribeirão Preto, SP, Brazil. Tel: +55-16-3602-4146, Fax: +55-16-3633-0999 e-mail: fabioromano@forp.usp.br 
it was also observed the debonding behavior regarding dental arches (maxillary and mandibular), sides (right and left), and quadrants for a 6-month period.

\section{MATERIAL AND METHODS}

Nineteen patients, 12 females and 7 males, with ages ranging from 10.5 to 38.7 years were selected for the study. All of them needed corrective orthodontic treatment and attended the Ribeirão Preto Dental School Orthodontic Clinic, and none of them had ever been subjected to any type of orthodontic therapy. Exclusion criteria were the following: patients needing ortho-surgical treatment, those with missing teeth, those needing dental extractions, and those presenting prosthetic crowns, extensive restorations, enamel defects and cranial-facial anomalies.

The buccal surfaces of all teeth were cleaned using nonfluoridated pumice and water for $10 \mathrm{~s}$. The teeth were also polished using a rubber cup, abundantly washed, and dried using an air syringe free of oil and moisture. Next, Transbond Plus-SelfEtching Primer(TPSEP; 3M Unitek) was applied and rubbed on the enamel surfaces for approximately three seconds. An air jet was slightly applied to the enamel. Each TPSEP package was enough to 10 prepared teeth, being discarded after that.

Three hundred and eighty brackets (Morelli, Sorocaba, SP, Brazil) were bonded on maxillary and mandibular teeth, being 190 with TXT composite (control) and 190 with TPCC (experimental) composite in contralateral quadrants. All bonding procedures were performed by the same operator. Excess bonding material was removed with a scraper and light curing was done for $40 \mathrm{~s}$ ( $10 \mathrm{~s}$ for each tooth face - mesial, distal, incisal or occlusal border, and gingival) with a halogen light-curing unit (XL2500; 3M ESPE, St. Paul, USA) with an intensity of 550 $\mathrm{mW} / \mathrm{cm}^{2}$. The light-curing unit tip was distant $1 \mathrm{~mm}$ from each bracket face, and its intensity was calibrated for each polymerization cycle using a radiometer (Demetron, Danbury, CT, USA).

Figures $1 \mathrm{~A}$ and $1 \mathrm{~B}$ show bonding distribution of composites according to quadrants in patients from 1 to 10 and from 11 to 19 , respectively. Inversion in the position quadrants of the composites from the 11th patient was performed in order to avoid interference of environmental factors (e.g. masticatory force, occlusion, tooth brushing) with the debonding rate.

Following the bonding procedure and evaluation of occlusal interferences, bands were adapted and cemented on molars and initial alignment nickel-titanium archwires (0.012-inch) already inserted. The patients were instructed about oral hygiene, diet and care with appliance so that debonding could be prevented from occurring accidently. The patients were evaluated every 21 days during 6 months to quantify the bond failure rates and proceed with the orthodontic treatment. Data were analyzed statistically by Kaplan-Meier method and log-rank test (Mantel-Cox).

\section{RESULTS}

Six bond failures occurred, $3(1.57 \%)$ in the control quadrants (TX) and $3(1.57 \%)$ in the experimental ones (TPCC) (Table 1). Statistical analysis by both Kaplan-Meier method (Fig. 2) and log-rank test revealed no statistically significant difference between the materials $(\mathrm{p}=0.999)$.

The bond failure rates between dental arches (maxillary and mandibular) were also assessed, where

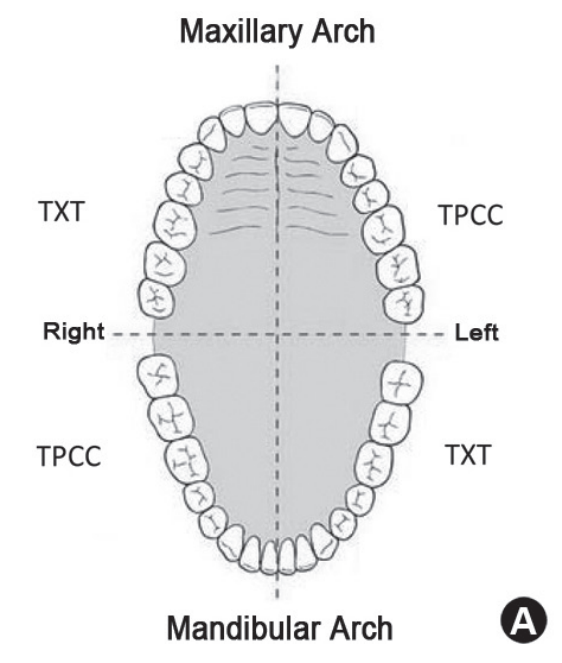

Figure 1. Bonding distribution of composites according to quadrants in patients from 1 to 10 (A) and from 11 to 19 (B).

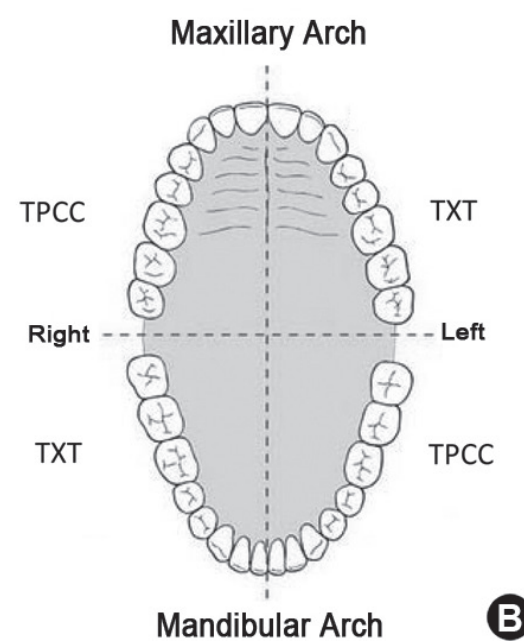

B 
3 brackets debonded from each arch. In addition, 4 bond failure were observed on the right side and 2 on the left side. With regard to the quadrants, 2 bond failures were observed in the maxillary right quadrant, 2 in the mandibular right quadrant, 1 in the maxillary left quadrant, and 1 in the mandibular left quadrant. Figure 3 shows the bracket debondings during the evaluation period.

\section{DISCUSSION}

The TXT composite has been developed specifically for bonding orthodontic brackets due to its adequate enamel adhesion, being largely used in laboratory (4-7) and clinical (8-15) studies as a control. In the present investigation, this composite was used to bond 190 brackets, and a bond failure rate of $1.57 \%$ (Table 1) was found over a 6-month period. This value below $10 \%$ corroborates the clinical use of such a material (17). Other works $(8,14,18,19)$ have also found similar debonding rates regarding this composite in association with TPSEP.

TPCC is a new orthodontic composite that has been recently developed and is characterized by its pink color, which changes to transparent following

Table 1. Bond failure rates with composites.

\begin{tabular}{lccc}
\hline Composites & $\begin{array}{c}\text { Brackets } \\
\text { bonded }\end{array}$ & $\begin{array}{c}\text { Number of } \\
\text { failures }\end{array}$ & $\begin{array}{c}\text { Failure rate } \\
(\%)\end{array}$ \\
\hline TXT & 190 & 3 & 1.57 \\
TPCC & 190 & 3 & 1.57 \\
\hline
\end{tabular}

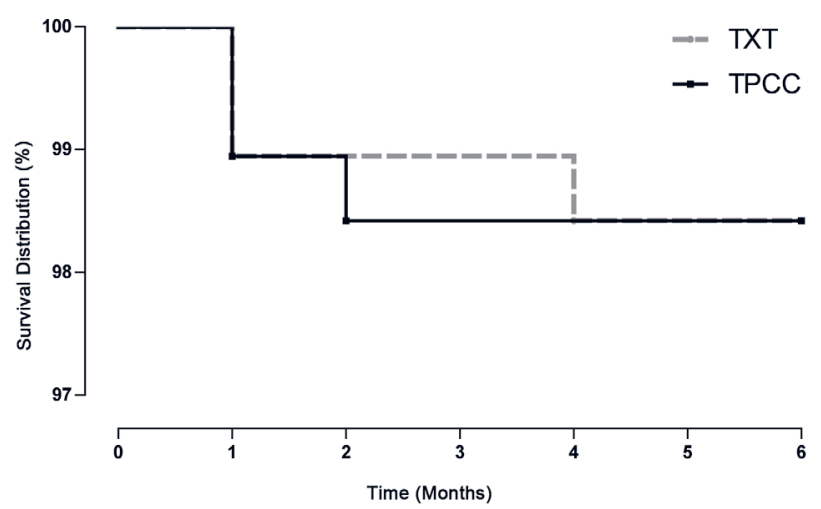

Figure 2. Statistical results (Kaplan-Meier test). photoactivation, in addition to having hydrophilic properties and allowing fluoride release $(16,20)$. In the present clinical study, three bond failure were observed (Table 1) during the study period. In their in vitro study, Romano et al. (16) evaluated the shear bond strength of this composite using different enamel preparations. When combined with TPSEP, the composite had a mean shear bond strength value of $17.5 \mathrm{MPa}$. Because such a material has been recently launched to the market, there is a lack of clinical studies to compare with the results found in our work. Despite not being the objective of the present study, it was observed that TPCC is very sensitive to natural light, changing its color very easily. This finding shows that color change is a relative advantage regarding the removal of composite excess. It is worth pointing out that the orthodontist needs to handle the composite, position the bracket and remove material excess, which are all clinical steps performed under natural and artificial light.

Although TXT and TPCC composites are similar, there are indeed small differences in their formulations and proportions as the former has 14\% BIS-GMA, 9\% BIS-EMA and $77 \%$ load particles, whereas the latter has $12 \%, 8 \%$ and $80 \%$ of the same components, respectively. However, such differences in proportion seem to have no influence on the adhesiveness of both materials, since no significant difference was found between them in this clinical investigation.

In conclusion, a few metallic brackets debonded in relation to the application of either TXT or TPCC in the bonding procedures using TPSEP as enamel conditioner. The obtained results suggest that the new composite can be indicated for clinical purposes, but some of its

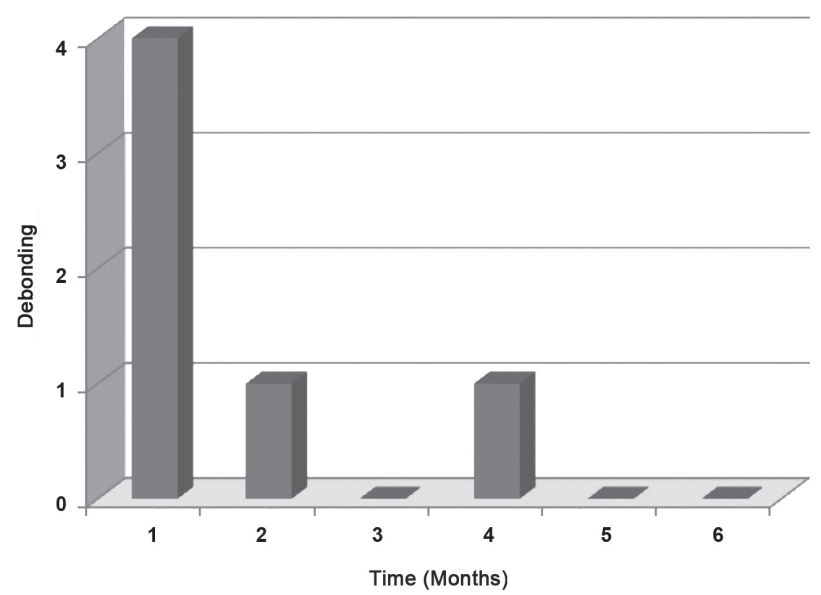

Figure 3. Bracket debonding during the 6-month evaluation period. 
characteristics, such as color stability, water tolerance, and fluoride release still need further investigation.

\section{RESUMO}

O objetivo do presente estudo foi avaliar in vivo a taxa de falha de braquetes metálicos colados com dois compósitos ortodônticos. Dezenove pacientes com idades entre 10,5 e 38,7 anos, que necessitavam de tratamento ortodôntico corretivo, foram selecionados para estudo. As superfícies de esmalte de segundos pré-molares a segundos pré-molares foram tratadas com Transbond Plus Self-Etching Primer (3M Unitek). Em seguida, 380 bráquetes foram colados nos dentes superiores e inferiores, como segue: 190 com compósito Transbond XT (3M Unitek) (controle) e 190 com Transbond Plus Color Change (3M Unitek) (experimental), em quadrantes contralaterais. Os bráquetes colados foram fotopolimerizados por $40 \mathrm{~s}$ e arcos de alinhamento inicial foram inseridos. As taxas de insucesso na adesão foram registrados durante um período de seis meses. No final da avaliação, seis falhas de adesão ocorreram, três para cada composto. Para a análise estatística foram utilizados os testes de Kaplan-Meyer e log-rank (Mantel-Cox), e não houve diferença estatisticamente significante entre os materiais $(p=0,999)$. Ambos compósitos, Transbond XT e Transbond Plus Color Change, tiveram baixas taxas de descolagem durante o período de estudo.

\section{REFERENCES}

1. Bishara SE, VonWald LBA, Laffoon JF, Warren JJ. The effect of repeated bonding on the shear bond strength of a composite resin orthodontic adhesive. Angle Orthod 2000;70:435-441.

2. Bishara SE, Laffoon JF, VonWald L, Warren JJ. The effect of repeated bonding on the shear bond strength of different orthodontic adhesives. Am Orthod Dentofacial Orthop 2002;121:521-525.

3. Newman G. Epoxy adhesives for orthodontics attachments: progress report. Am J Orthod 1965;51:901-912.

4. Chapman JL. Bond failure rates of two self-ligating brackets: a randomised clinical trial. Aust Orthod J 2011;27:139-144.

5. Arnold RW, Combe EC, Warfor Jr JH. Bonding of stainless steel brackets to enamel with a new self-etching primer. Am J Orthod Dentofacial Orthop 2002;122:274-276.

6. Buyukyilmaz T, Usumez S, Karaman AL. Effect of self-etching primers on bond strength - are they reliable? Angle Orthod 2003;73:64-70.
7. Romano FL, Tavares SW, Consani S, Magnani MBBA, Nouer DF. Shear bond strength of metallic orthodontic brackets bonded to enamel prepared with self-etching primer. Angle Orthod 2005; 75:849-853.

8. Asgari S, Salas A, English J, Powers J. Clinical evaluation of bond failure rates with a new self-etching primer. J Clin Orthod 2002;36:687-689.

9. Ireland $\mathrm{AL}$, Knight $\mathrm{H}$, Sherriff $\mathrm{M}$. An in vivo investigation into bond failure rates with a new self-etching system. Am J Orthod Dentofacial Orthop 2003;124:323-326.

10. Cal-Neto JP, Miguel JAM. An in vivo evaluation of bond failure rates with hydrophilic and self-etching primer systems. J Clin Orthod 2005;39:701-702.

11. Pandis N, Christensen L, Eliades T. Long-term failure rate of molar tubes bonded with a self-etching primer. Angle Orthod 2005;75:1000-1002.

12. Murfitt PG, Quick AN, Swain MV, Herbison GP. A randomized clinical trial to investigate bond failure rates using a self-etching primer. Eur J Orthod 2006;28:444-449.

13. Pasquale A, Weinstein M, Borislow AJ, Braitman LE. In-vivo prospective comparison of bond failure rates of 2 self-etching primer/adhesive systems. Am J Orthod Dentofacial Orthop 2007;132:671-674.

14. Elekdag-Turk S, Isci D, Turk T, Cakmak F. Six-month bracket failure rate evaluation of a self-etching primer. Eur J Orthod 2008;30:211-216.

15. Reis A, Santos JE, Loguercio AD, Bauer JRO. Eighteen-month bracket survival rate: conventional versus self-etch adhesive. Eur J Orthod 2008;30:94-99.

16. Romano FL, Correr AB, Sobrinho LC, Magnani MBB, Siqueira VCV. Shear bond strength of metallic brackets bonded with a new orthodontic composite. Braz J Oral Sci 2009;8:76-80.

17. Brantley WA, Eliades T. Orthodontic materials: scientific and clinical aspects, Thieme, Stuttgart, Germany, 2001.

18. Pandis N, Eliades T. A comparative in vivo assessment of the long-term failure rate of 2 self-etching primers. Am J Orthod Dentofacial Orthop 2005;128:96-98.

19. Romano FL, Correr AB, Correr-Sobrinho L, Magnani MBBA, Ruellas ACO. Clinical evaluation of the failure rates of metallic brackets. J Appl Oral Sci 2012;20:228-234.

20. Passalini P, Fidalgo TK, Caldeira EM, Gleiser R, Nojima M da, C, Maia LC. Preventive effect of fluoridated orthodontic resins subjected to high cariogenic challenges, Braz Dent J 2010;21:211215.

Received January 14, 2011

Accepted August 14, 2012 